\title{
REVIEW OF THE TRADITIONAL USES, PHYTOCHEMISTRY, TOXICOLOGY AND PHARMACOLOGY OF FENUGREEK (TRIGONELLA FOENUM-GRAECUM L.): AN IMPORTANT MEDICINAL PLANT IN UNANI MEDICINE
}

\author{
Shabnam Anjum Ara ${ }^{1}$, Shaheen Akhlaq ${ }^{1}$, Mohammad Fazil ${ }^{2}$, \\ Usama Akram ${ }^{3}$ Bilal Ahmad ${ }^{3}$, Merajul Haque ${ }^{3}$, Ahmad Sayeed ${ }^{3}$ and Asim Ali Khan ${ }^{4}$ \\ ${ }^{1}$ Senior Research Fellow, Hakim Ajmal Khan Institute for Literary \& \\ Historical Research in Unani Medicine, CCRUM, JMI Campus, New Delhi \\ ${ }^{2}$ Assistant Director (Incharge), Hakim Ajmal Khan Institute for Literary \& \\ Historical Research in Unani Medicine, CCRUM, JMI Campus, New Delhi \\ ${ }^{3}$ Research officer, Hakim Ajmal Khan Institute for Literary \& \\ Historical Research in Unani Medicine, CCRUM, JMI Campus, New Delhi \\ ${ }^{4}$ Director General, Central Council for Research in Unani Medicine, Janakpuri, New Delhi
}

Review Paper

Received: 25.09.2021

Revised: 10.10.2021

Accepted: 20.10.2021

ABSTRACT

Background: Trigonella foenum-graecum L. with common name fenugreek, is a very popular spice as well as an important herb of traditional Unani medicine. It is one of the most promising herbs having nutritional as well as medicinal value, used for the treatment of an extensive range of ailments.

Objective: The aim of the review is to present the traditional uses, phytochemistry, toxicology in the light of Unani medicine as well as contemporary researches to comprehend its importance.

Methods: The literature was collected from classical Unani texts such as Khazain al-Advia, Makhzan al-Advia, Muhit-i-Azam, Al-Jami li Mufradat al- Advia wa'l Aghziya, Al Qanoon Fit Tib etc., and scientific data from published experimental and clinical studies were searched from search engines like Scopus, Web of science, Embase, Google scholar, Pub Med etc.

Results: Phytochemical studies have led to the isolation of different compounds such as alkaloid, flavonoids, saponin, volatile contents, gum and fibre. Fresh plant ingredients such as seed, leaves etc, crude extracts and isolated constituents of fenugreek showed a wide spectrum of in vitro and in vivo studies that embrace its hypoglycaemic, anti-inflammatory, antioxidant, and cytotoxic activities.

Conclusion: With its vast mode of action, it influences in multip le ways in treatment of the diseases and the present review revealed its therapeutic potential and status. For future research prospects, the need of further studies involving mechanisms of action on scientific parameters is essential.

No. of Pages: $10 \quad$ No. of Tables: $3 \quad$ No. of Figures: 1

References: 27

Keywords: Trigonella foenum-graecum L., Fenugreek, Traditional, Unani, Phytochemistry.

*Corresponding author: drshabnam3009@gmail.com 
Traditional medicine involves alleviation of illnesses through natural methods. In ancient times, herbs were the prime source of the healthcare system as no option were available back then. As the modern researches took control, the popularity of herbal medicine declined to a great extent but gradually gained momentum again as people find it more efficacious, tolerable as well as safe when compared to synthetic drugs. Plants had been used for medicinal purposes long before recorded history and further advances in the field of research show the worth of herbal medicine in the treatment and prevention of the diseases. Unani medicine is recognised by World Health Organization (WHO) and popular in South Asian countries and has now become part of the mainstream system of medicine in Bangladesh, India, Islamic Republic of Iran, Pakistan, and others. It encompasses a wide range of practices, the regimental therapy includes venesection, cupping, diaphoresis, diuresis, Turkish baths, massage, cauterization, purging, emesis, exercise and leeching etc. to help balance the homeostasis of the body. Dietotherapy in Unani medicine deals with precise diets by regulating the quantity and quality of food. Likewise, pharmacotherapy include natural-based drugs, mostly plant origin, also animal and mineral origin as single drug or formulation, raw form being preferred over compound preparations ${ }^{1}$. Unani system of medicine offers scientific and time-tested therapies for the treatment of diseases, preservation and promotion of health. The system has survived for centuries due to its in-built potency and efficacy of the various natural therapeutic regimens. The basic principles of Unani medicine focus on holistic approach and cover all medical field, i.e., anatomy, physiology, pathology, diagnostics, preventive medicine, pharmacology and therapeutics ${ }^{2}$. India is one of the few nations where almost all the known herbs with are cultivated in some part of the country or the other. Medicinal plants rich in secondary metabolites such as alkaloids, glycosides, coumarins, flavonoids etc, are potential source of drugs. The bioactive compounds present in herbs mediate their effect through methods similar to those already well understood in conventional system of medicine; thus, herbal medicines do not differ greatly from conventional medicine in terms of pharmacokinetics and pharmacodynamics. There are some herbs that are used for both culinary and medicinal purposes. Fenugreek, belonging to family Papilionaceae is one such important herb extensively used for its varied significance. Fenugreek is "generally recognized as safe" (GRAS) as a flavouring by the U.S. Food and Drug Administration and it has a long history of use as a food and medicine in India and China. When used as a medicine, it is generally well tolerated in adults, but gastrointestinal side effects such as nausea, vomiting, diarrhoea and flatulence may occur ${ }^{3}$. Basically, it is a dried ripe fruit of an annual herb, native of South-eastern Europe and West Asia and cultivated in India, Argentina, Egypt, Mediterranean countries (Southern France, Morocco and Lebanon). India is one of the major producers and exporters of fenugreek.

Table 1: Morphology of Fenugreek (Trigonella foenum-graecum L.) ${ }^{4}$

\begin{tabular}{|c|c|}
\hline Macroscopic characteristics & Microscopic characteristics \\
\hline 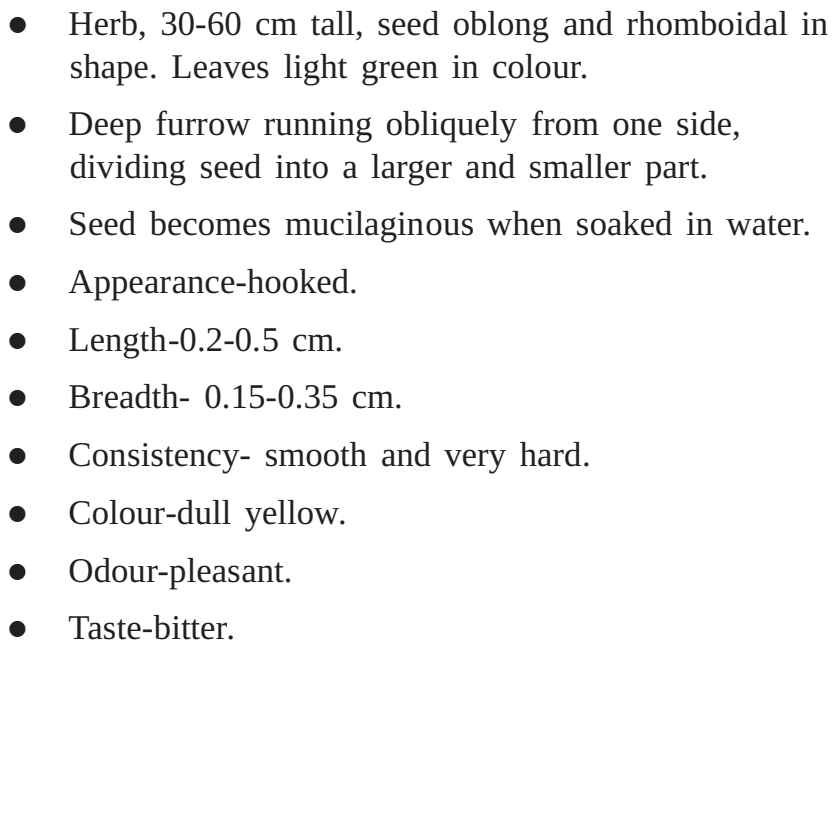 & $\begin{array}{l}\text { - Seed displays a layer of thick-walled, columnar } \\
\text { palisade cells, covered externally with thick cuticle. } \\
\text { - Cells flat at base, supported internally by a } \\
\text { tangentially wide bearer cells having radiameter l } \\
\text { rib-like thickenings followed by } 4-5 \text { layers of } \\
\text { tangentially elongated, thin-walled, parenchymatous } \\
\text { cells. } \\
\text { - Endosperm consists of aleurone grains, } \\
\text { - } \\
\text { Numerous layers of thin-walled, mucilaginous cells. } \\
\text { and consists of 3- } 4 \text { layers of palisade cells and a } \\
\text { few layers of rudimentary spongy tissue, situated in } \\
\text { spongy mesophyll. } \\
\text { Powder, yellow in colour shows groups of palisade } \\
\text { parenchymatous cells, aleurone grains, oil globules, } \\
\text { endosperm and epidermal cells of testa. }\end{array}$ \\
\hline
\end{tabular}


Table 2: Synonyms of Fenugreek (Trigonella foenum-graecum L.) ${ }^{4,6}$

\begin{tabular}{|l|l|}
\hline Arabic: Hulba & Kannada: Menthe, Mente \\
\hline Urdu: Methi & Malayalam: Uluva \\
\hline Persian: Shamleet & Marathi: Methi \\
\hline English: Fenugreek & Punjabi: Methi \\
\hline Hindi: Methi & Tamil: Mendium, Ventaiyam \\
\hline Gujarati: Methi & Telugu: Mentulu \\
\hline
\end{tabular}

Temperament $^{4,6}:$ Hot and Dry

Part Used $^{5}$ : Seed, leaf

$\operatorname{Dose}^{4}: 3-5$ g

Preservation and storage ${ }^{6:}$ Sun dried seeds are preserved and stored in moisture free place as they contain mucilage. They can be stored for two years.

\section{Phytochemistry (Bioactive constituents)}

Trigonella foenum-graecum L. is rich in valuable bioactive molecule which add its importance in therapeutics. The chief chemical constituents present are alkaloid, coumarins, sapogenins, and mucilage. Saponins, a class of glycosylated triterpenes include two major constituents, diosgenin and yamogenin. It also contains 35\% alkaloids, primarily trigonelline with high therapeutic potential, polyphenolic compounds, like flavonoids (kaempferol, quercetin) and coumarins like scopoletin and lactone orthodihydroxy cinnamic acid too. Diosgenin, a steroid saponin, trigonelline, an alkaloid, galactomannan, a polysaccharide gum, 4hydroxyisoleucine, sotolon, luteolin, phenolic acids, and protodioscin has immense benefits. Due to the presence of the chemical constituent, fenugreek is one of the well-known herbal drugs that have antioxidant, hypoglycaemic, immunomodulatory, and hypolipidemic potential ${ }^{7}$. The seeds of fenugreek contain gums (23.06\%) and mucilage (28.00\%). Several constituents like protein, starch, sugars, mineral matter, volatile oil, fixed oil, vitamins and enzymes are also present. Seeds are rich in essential amino acids and are a very good source of protein. Fenugreek leaves and stems are also rich in calcium, iron, carotene and ascorbic acid. The fatty acids present consist largely of linoleic, oleic and linolenic acids. The fixed oil content is about $7 \%$, volatile oil content about $0.02 \%$. protein about $9.5 \%$, fat about $10.0 \%$, crude fibre about $18.5 \%$, carbohydrates about $42.3 \%$, calcium about $1.3 \%$, phosphorus about $0.48 \%$, iron about $0.011 \%$, sodium about $0.09 \%$, potassium about $1.7 \%$, vit. A about 1,040 I.U./100g, vit. $\mathrm{B}_{1}$ about $0.41 \mathrm{mg} / 100$, vit. $\mathrm{B}_{2}$ about 0.36 , vit. $\mathrm{C}$ about 12.0 and niacin about $6.0 \mathrm{mg} / 100 \mathrm{~g}^{8}$.

\subsection{Toxicology}

Besides innumerable medicinal properties, fenugreek have toxicological side effects as well. The literature of Unani medicine reports about the toxic effects encountered with the use of fenugreek such as syncope and headache. Galen, a great Unani scholar enlightened its ill effects that if consumed in excess leads to dyspepsia and recommend that it should not be eaten in all seasons and neither should it fill the stomach $^{9}$. It is also mentioned that it is harmful for testis and people with hot temperament ${ }^{10}$. The ancient knowledge provided by Unani medicine is well supported by the contemporary researches. Saponins are known to exhibit antifertility activity and cause teratogenicity through their oestrogenic and androgenic activities. Testicular toxicity and anti-fertility effects in rat, mouse and rabbit revealed toxic properties of Trigonella foenum-graecum L. to produce oxidative stress and DNA damage. Flavonoids present in the seed at higher doses readily cross the placenta and causes the development of reactive oxygen species, and ultimately DNA damage triggering risks to foetal growth. Potent teratogenic effects are documented including a variety of birth defects such as major malformations, growth alterations, functional developmental deficits. Additionally, coumarins in fenugreek seeds affect platelet aggregation, increase the risk of bleeding and enhance the activity of other anticoagulants, like warfarin and some cases of hepatotoxicity have also been reported from patients treated with coumarin. In preliminary human trials, the consumption of fenugreek give rise to adverse side effects such as diarrhoea, dyspepsia, abdominal pain, flatulence and hypoglycaemia. Studies in animal models suggest a low acute toxic potential of fenugreek by oral route at 2 and $5 \mathrm{~g} / \mathrm{kg}$ bw in mice and rats respectively and by intraperitoneal route at 0.65 and $3.5 \mathrm{~g} / \mathrm{kg}$ bw in mice and rats respectively. It is also reported to be at risk in patients known to be allergic to it or who are allergic to chickpeas or peanut because of possible cross-reactivity as well as in severe asthma. Moreover, fenugreek is also known to be responsible for neuropathological abnormalities ${ }^{11}$.

\section{Substitutes ${ }^{6}$ \\ - Linseed / Alsi (Linum usitatissimum L.) \\ - Tonkin Bean / Iklil-ul-Malik (Trigonella uncata Boiss.)}




\section{Correctives $^{6}$}

- Sikanjabeen Tursh (Vinegar-lemon drink)
- Anisoon (Pimpinella anisum L.)

- Leaves of Kasni (Cichorium intybus L.)

Table 3: Identity, Purity and Strength of Fenugreek (Trigonella foenum-graecum L.) ${ }^{4,6}$

\begin{tabular}{|l|}
\hline Foreign matter: Not more than 2 per cent \\
\hline Total ash: Not more than 4 per cent \\
\hline Acid-insoluble ash: Not more than 0.5 per cent \\
\hline Alcohol-soluble extractive: Not less than 5 per cent \\
\hline $\begin{array}{l}\text { TLC profile: Thin Layer Chromatography observed under Ultra violet light: with Acetone extract, chloroform: ethyl acetate: } \\
\text { formic acid (50:40:10) showed one spot at Rf 0.44; with Ethanol extract, chloroform: ethyl acetate: formic acid (50:40:10) } \\
\text { showed one spot at Rf } 0.27 \text {; with Ethanol extract, chloroform: methanol: water (35:13.5:1.8) showed one spot at Rf 0.26. }\end{array}$ \\
\hline
\end{tabular}

In the present paper, we aimed to review the traditional uses, pharmacology, phytochemistry and toxicology of this ancient medicinal herb.

\section{METHODOLOGY}

The work was conducted at Hakim Ajmal Khan Institute for Literary \& Historical Research in Unani Medicine, New Delhi. The data collected were manuscripts of Unani medicine such as Al Qanoon Fit Tib, Khazain al-Advia, Makhzan al-Advia, Kitab al-Hawi, Muhit-i-Azam, Al-Jami li Mufradat al- Advia wa'l Aghziya, etc. The accurate illustration of the Unani terminologies were taken from Standard Unani Medical Terminology published by the Central Council for Research in Unani Medicine in collaboration with World Health Organization for the preparation of the manuscript ${ }^{12}$. Relevant studies concerning various pharmacological activities of fenugreek were searched through electronic search using PubMed, Google Scholar, Scopus, Cochrane Library and Web of Science without time limit. Keywords used for the search were 'trigonella, 'hepatoprotective', 'galactagogue', 'antioxidant', etc.

\section{RESULTS AND DISCUSSION}

Plant-derived natural products have a long-standing utility in the treatment of the diseases. The importance of fenugreek in traditional medicine especially Unani medicine can be well traced with its usage since antiquity. Scholars and scientists of Unani medicine identified the immense pharmacological benefits and used the various parts of fenugreek to treat several disorders. The scientific explanation of the health-promoting effects of the herb has been validated by different studies and trials conducted at innumerable research organizations.

\section{Pharmacological actions ${ }^{4,6}$}

Unani system of medicine utilizes this herb since antiquity for a number of ailments and the known pharmacological actions are as follows-
- Jāli (Detergent)

- Mulațif (Demulcent)

- Muhallil-i-Auram (Anti-inflammatory)

- Muqawwī-i-A'șāb (Nervine tonic)

- Muqawwi-i-Bāh (Aphrodisiac)

- Munaffith-i-Balgham (Expectorant)

- Mudirr-i-Hayḍ (Emmenagogue)

- Mudirr-i-Bawl (Diuretic)

- Kāsir-i-Riyaḥ (Carminative)

- Mulayyin (Laxative)

\section{Therapeutic uses}

Medicinal uses: The seed is produced as a spice but it's been widely used as a vegetable for human consumption, as forage for cattle and, for medicinal purposes too. Medical papyri from ancient Egyptian tombs reveal that it was used both to reduce fevers and also consumed as a food. Fenugreek seeds in particular are used as carminative, tonic, aphrodisiac, stimulates the digestive process as well as the metabolism in general and used in colic, flatulence, dysentery, diarrhoea, dyspepsia with loss of appetite, chronic cough, rickets, gout, dropsy, diabetes and enlargement of liver and spleen. Infusion is known to be helpful in small pox patients as a cooling drink, also used in sweets served to ladies during the post-natal period and promote lactation as well ${ }^{8}$. In the absence of a reference galactagogue molecule, the use of plant extracts has grown rapidly with nowadays $15 \%$ to $25 \%$ of mothers using herbal remedies to upsurge their milk supply in Western countries, and among them fenugreek is the most consumed, accounting for $50 \%$ of the plant extracts taken during breastfeeding ${ }^{13}$. Furthermore, recent studies report that diosgenin is used as a starting material in the synthesis of sex hormones and oral 
contraceptives and it is anticipated that if plant breeders are successful in developing fenugreek varieties with a high content of diosgenin, this herb could make a two-fold economic contribution to a solution of the world's population problems by assisting in birth control and at the same time providing additional food. In Unani system of medicine, it is used in a variety of disorders such as Ashob-i-Chashm (Conjunctivitis), Sual (Cough), Zeeq-un-Nafs (Asthma), Ihtibās-i-Hayḍ (Cessation of menstruation), Zof-i- Bāh (Sexual debility), Zof-i- A'șāb (Nerves weakness), Waja'ul-Mafāṣil (Rheumatoid arthritis) ${ }^{4}$ etc. Flour of fenugreek when prepared act as anti-inflammatory in splenitis. The anti-inflammatory effect of fenugreek flour is also helpful in resolving abscess. Decoction of it relives pain of uterus and used as sitz bath. Fenugreek act as hair growth stimulant and its extract is helpful in dandruff and resolve many hair problems. Fenugreek provide nutrient to the lungs and perform expectorant action for its proper functioning. Fresh fenugreek when consumed act as haematinic and help to correct anaemia. When nails become dry and wrinkled due to excessive cold or heat, local application of fenugreek proved beneficial. For cosmetological purposes, it is widely used in Unani medicine for melasma and as beauty enhancers ${ }^{9}$. It is also reported that dribbling of urine due to excessive cold is corrected by giving fenugreek seed with honey as semisolid preparation, 7gm at bedtime. In addition to this, it also acts as galactagogue when applied as paste on mammary glands and used extensively in Unani medicine to help in lactation and as puerperal tonic. It is also a part of regimen in infancy period in the treatment of skin by the use of salted water to protect the sensitive infant's skin and the best agents to employ for this purpose include shādnaj (bloodstone), bitter costus, sumach, fenugreek and origanum ${ }^{14}$. A semisolid nutritive preparation obtained by mixing fenugreek seed in a base of jaggery is reported to be effective in rheumatoid arthritis. The decoction of fenugreek seed is helpful for the stoppage of bleeding haemorrhoids. The oil obtained from fenugreek seed has various benefits, found advantageous as local application in alopecia, piles and dryness of skin. For skin dryness, it is mixed with wax and applied all over the body for moisturizing effect ${ }^{10}$. Fenugreek is also reported to be a general body tonic, analgesic for chest pain, appetizer for anorexia, insecticidal for worm infestations ${ }^{15}$.

Uses as Food/ Food Flavourant: Fenugreek is used both as a food or food additive and is one of the principal odorous constituents of curry powder. Since ancient times, fresh tender pods, leaves and shoots rich in iron, calcium, protein, vitamin A and vitamin $\mathrm{C}$, are eaten as curried vegetable. Fenugreek seed, when used as a spice also adds the nutritive value. In the northern part of India, it forms an important ingredient in 'mango pickle in oil'. In Egypt and Ethiopia, fenugreek is a popularingredient of bread, known to the Arabs as 'Hulba', and in Ethiopia going by the Amharic name 'Abish'. In Greece, where Unani medicine originated, the practice of fenugreek seeds, boiled or raw, are habitually eaten with honey. In the United States, it is used in the manufacture of chutneys and in various spice blends, but its most important culinary use is as a source of fenugreek extract, the principal flavouring ingredient of imitation maple syrup. Moreover, it is used in recipes like hearty vegetable bean soup and fenugreek beef stew ${ }^{8}$.

Uses in cattle food and veterinary medicine: Various veterinary medicinal preparations contain fenugreek. It is fed to cows to increase the flow of milk and used as ground fine when mixed with cotton seed. Mildewed or sour hay is made palatable to cattle when fenugreek herbage is mixed with it. It is also used as a conditioning powder to produce a glossy coat on horses ${ }^{8}$.

Uses in cosmetic industry: Fenugreek is recommended as a cure for baldness in men and is considered important in trichology. In Java, it is used in hair tonic preparations and as a cosmetic. The powder made from the seeds is used in the Far East as a yellowish dye. Harem women in North Africa and the Middle East roast the seeds to achieve a captivating buxom plumpness. It contains fixed oil which has an overpowering celery-like odour known to be extremely tenacious and in recent years, has attracted the interest of the perfume trade $^{8}$.

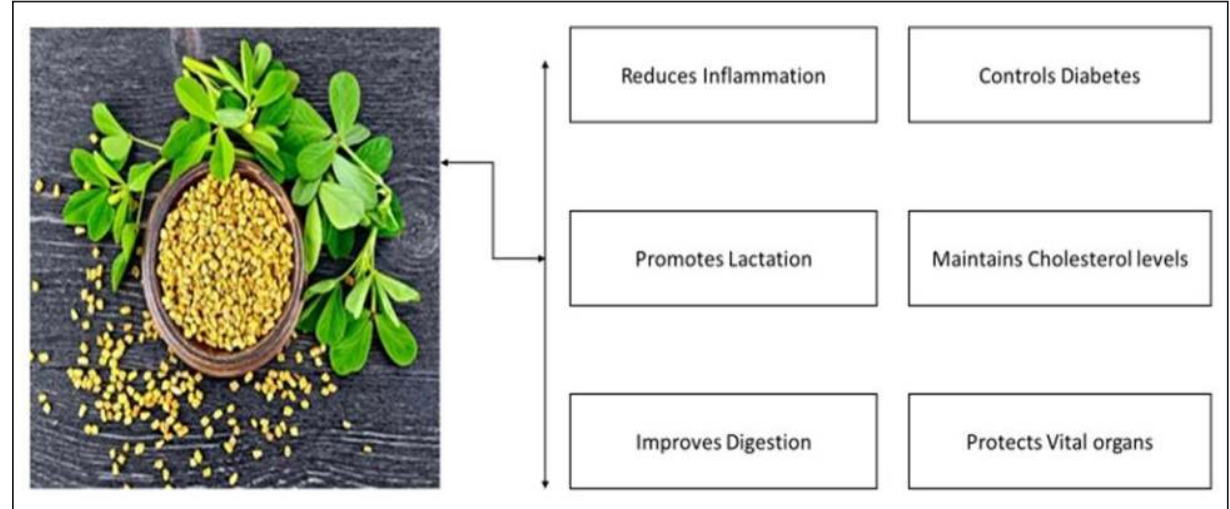

Figure 1: Important therapeutic applications of Fenugreek. 


\section{Important traditional Unani formulations containing Fenugreek $^{4,6}$}
- Habb-i-Khabsul Hadid
- Laooq Habb-ul-Sanobar
- Qairooti Aarad Karsana
- Marham Dakhilyoon
- Dawa-ul Misk.

\section{Reported Pharmacological Studies}

- Antioxidant activity: The study established significant antioxidant activity of different fractions of germinated fenugreek. The assays used were ferric reducing antioxidant power, oxygen radical absorbance capacity, radical scavenging by 1,1-diphenyl-2-picrylhydrazyl, ferrylmyoglobin/ 2,2'-azobis-3-ethylbenzthiazoline-6sulfonic acid, pulse radiolysis, and inhibition of lipid peroxidation in mitochondrial preparations from rat liver. HPLC technique was used to detect flavonoids, polyphenols, and other components. Results revealed the maximum antioxidant activity in aqueous fraction of fenugreek when compared with other fractions ${ }^{16}$. In another study on 12-months aged mice, fenugreek seed dietary supplement was assessed for antioxidant defence enzymes such as superoxide dismutase (SOD), glutathione reductase (GR), and glutathione peroxidase (GPx), and also estimated the phenolics and free radical scavenging activities in mice liver. The estimation of SOD, GPx, and GR activities in aged mice liver revealed a significant $(p<0.01)$ difference among all the liver enzymes and study revealed a positive effect on the activities of the hepatic antioxidant defence enzyme ${ }^{17 .}$

- Immunomodulatory activity: Aqueous extract of fenugreek was used for immunomodulatory activity in male Swiss albino mice. Four groups, each with minimum of five animals were treated with three doses of extract (50, 100 and $250 \mathrm{mg} / \mathrm{kg}$ body weight per os) for 10 days. There were four groups involved, group I, control; group II, plant extract $50 \mathrm{mg} / \mathrm{kg}$ bw; group III, plant extract $100 \mathrm{mg} / \mathrm{kg}$ bw; and group IV, plant extract $250 \mathrm{mg} / \mathrm{kg}$ bw. Parameters such as body weight, relative organ weight, cellularity of lymphoid organs, delayed type of hypersensitivity response, haemagglutination titre, quantitative haemolysis of SRBC assay, plaqueforming cell assay, lymphoproliferation and phagocytosis were examined. Results revealed an overall stimulatory effect at $100 \mathrm{mg} / \mathrm{kg}$ body weight and in some cases at $250 \mathrm{mg} / \mathrm{kg}$ dose of fenugreek on the specific as well as nonspecific immune functions ${ }^{18}$. Another study on adult male Wistar albino rats that have three immunosuppressive groups were given the low or high dose of fenugreek seed powder (FSP) orally and daily for 4 weeks and received a single intraperitoneal injection ( $25 \mathrm{mg} / \mathrm{kg}$ body weight) of CP on day 24 (i.e. 6 d before killing the animals) to induce immunosuppression showed that FSP (especially the high dose) completely modulated the immuno-suppressive activity of CP including leucopenia, the decrease in weights and cellularity of lymphoid organs, the deficiency in humoral and cellular immune responses (as indicated by the decrease in the serum g-globulin level and delayed type of hypersensitivity response) and the delay in the skin-burning healing process and the immunosuppressive activity of CP decreased by $57-108 \%$ in the FSP-treated animals. Therefore, the study concluded that FSP may reduce the incidence of infections in cancer patients treated with such chemotherapeutic agents ${ }^{19}$.

- Hypoglycaemic activity: A parallel randomized eightweek clinical study of fenugreek seed on serum irisin levels, blood pressure, and hepatic and renal function in type 2 diabetes mellitus patient was measured. 50 patients were assigned to $5 \mathrm{~g}$ fenugreek seed powder thrice a day and a control group was taken. Blood investigations were collected and blood pressure was measured at baseline and termination of the study. Comparative study revealed that fenugreek seed consumption resulted in a significant reduction in fasting plasma glucose (FPG) as well as a significant variation in serum alanine aminotransferase (ALT) and alkaline phosphatase (ALP) when compared to control. Scrutiny within the group exhibited a significant decrease in aspartate aminotransferase (AST), systolic blood pressure (SBP), and irisin levels, and a significant rise in creatinine level and reduction in estimated glomerular filtration rate in the control group. The study proved beneficial effects of fenugreek seeds on plasma glucose, blood pressure, and some hepatic and renal function tests in type 2 diabetes mellitus patients ${ }^{20}$. The natural anti-diabetic agents with relatively low toxicity such as saponins, especially the dioscin or diosgenin is found in fenugreek seed. Thus, in vitro study was performed to purify the saponins and sapogenins as well as to assess their $\alpha$-glucosidase inhibitory activity. NMR spectroscopic analyses, high-resolution mass spectrometry, and chemical evidence were utilized and the results revealed about thirty-three isolated steroidal saponins and sapogenins, including six undescribed ones and twenty-seven previously known components. Sapogenins 26, 27, 14 and saponins 18 and 23 noticeably inhibited $\alpha$-glucosidase at IC50 values of 15.16, 8.98, 7.26, 5.49 and $14.01 \mu \mathrm{M}$, respectively when compared to the positive control, which supported the therapeutic efficacy of fenugreek in the treatment of diabetes mellitus ${ }^{21}$. 
- Galactagogue activity: The study reports that fenugreek stimulates the expression of genes involved in milk synthesis and milk flow through modulation of insulin/GH/IGF-1 axis and oxytocin secretion. Longitudinal molecular mechanisms involved in milk synthesis/secretion in dams submitted to fenugreek supplementation, inguinal mammary, pituitary glands and plasma were isolated in forty-three rats nursing large 12 pups-litters and assigned to two groups i.e., control (CTL) and fenugreek-supplemented (FEN) diet, assessed during lactation. RT-PCR done at days 12 and 18 of lactation and the first day of involution to measure the relative expression of genes related to both milk synthesis and its regulation in the mammary gland and lactogenic hormones in the pituitary gland. The concentrations of plasma hormone were measured by ELISA. FEN diet induced two to three times higher fold variation in relative expression of several genes related to macronutrient synthesis (Fasn, Acaca, Fabp3, B4galt1, Lalba and Csn2) and energy metabolism (Cpt1a, Acads) and in IGF-1 receptor in mammary gland, mainly at day 12 of lactation. Significant increase in pituitary oxytocin expression and plasma insulin concentration $(+77.1 \%)$ were also noted. The findings finally suggest that the effect of fenugreek on milk production at mid-lactation may be mediated by a stimulation of insulin secretion and a modulation of the insulin/ GH/ IGF-1 axis, while its action on maintaining lactation until the first day of mammary involution could be due to its estrogenic effect. In addition to this, a study using the deuterium oxide enrichment method to measure milk secretion in a model of rat nursing large litters, it was found that dietary fenugreek at a dose of 1 $\mathrm{g} / \mathrm{kg}$ body weight/day increased milk production by $16 \%$ and offspring growth by $11 \%$ without any evidence for adverse metabolic effect on either dams or offspring ${ }^{13}$.

- Cardioprotective activity: The activity was studied in streptozotocin induced forty-two male diabetic rats at a dose of $60 \mathrm{mg} / \mathrm{kg}$ of streptozotocin (STZ) treated with three different doses of fenugreek seed extract (50, 100 and $200 \mathrm{mg} / \mathrm{kg}$ ) or metformin (300 mg/kg) for six weeks and controls were nondiabetic rats. Assessment of glucose, cholesterol, and triglycerides levels, oxidative stress markers and gene expression of ICAM1, Bax and $\mathrm{Bcl} 2$ were assessed in the cardiac tissues of the animals. Diabetic rats showed increased serum glucose, cholesterol and triglycerides levels, elevated markers of oxidative stress catalase (CAT), thiobarbituric acid-reacting substances (TBARS) levels, total thiol groups ( $\mathrm{SH}$ ), and superoxide dismutase (SOD) activity, and enhanced apoptosis cell death (ratio of Bax/Bcl2). Fenugreek seed extract presented cardioprotective activity and resulted in improved metabolism irregularities, attenuated oxidative stress and diminished index of apoptosis. The study validated significant therapeutic potential of fenugreek seed extract in cardiovascular disorders via ameliorating metabolic abnormalities and oxidative stress, and regulating the genes involved in apoptosis ${ }^{22}$.

- Anxiolytic activity: The study performed on mice by using methanolic extract of fenugreek seeds to evaluate anxiety, sedation and motor coordination. Anxiety was assessed by Hole board test and Light and dark transition models at different doses following fifteen days of oral feeding. Phenobarbitone induced sleeping time and Rota rod test were done to assess effect on sedation and motor coordination. In Hole board test, decreased number of head dips in mice at all the three doses were noticed. In Light and dark transition model, increased period spent in the light box and the number of moves between the two compartments at 100 and $200 \mathrm{mg} / \mathrm{kg}$ as compared to control animals were detected. No sedative effect was observed in phenobarbitone induced sleeping time. In Rota rod test, significant skeletal muscle relaxant effect at $200 \mathrm{mg} / \mathrm{kg}$ (at $90 \mathrm{~min}$ ) as compared to the control animals were found. Overall, the results showed significant antianxiety activity of fenugreek seeds that may be recommended for improved adverse effect profile when compared to diazepam ${ }^{23}$.

- Anti-inflammatory activity: Petroleum ether extract of fenugreek seeds were used and extracted by cold maceration. Gas-liquid chromatography (GLC) was employed and rats were tested against carrageenan and formaldehyde-induced paw oedema, complete Freund's adjuvant (CFA)-induced arthritis and cotton pelletinduced granuloma for anti-inflammatory and antiarthritic activities. Blood parameters reveals alterations in serum glutamic oxaloacetic transaminase (SGOT), serum glutamate-pyruvate transaminase (SGPT), and alkaline phosphatase (ALP) in liver and in cotton pelletinduced arthritic rats, serum too showed marked alterations. GLC of extract's composition revealed oleic acid to be $33.61 \%$, linoleic acid to be $40.37 \%$, and linolenic acid to be $12.51 \%$. With $0.5 \mathrm{~mL} / \mathrm{kg}$ petroleum ether extract of fenugreek seeds treatment, there was 37\% $(\mathrm{P}<0.05)$ and 85\% $(\mathrm{P}<0.05)$ decrease in inflammation of the paw in carrageenan and formaldehyde-induced paw oedema. In CFA-induced arthritis, a biphasic rise in paw volume followed by diminution was seen. In the weight of cotton pellets, $42.5 \%(\mathrm{P}<0.01)$ reduction was noticed and significant $(\mathrm{P}<0.01)$ drop in the elevated SGPT and ALP in serum and liver of petroleum ether extract of fenugreek seeds 
$(0.5 \mathrm{~mL} / \mathrm{kg})$ treated rats were seen. The study concluded on the significant anti-inflammatory and anti-arthritic activities of petroleum ether extract of fenugreek seeds mainly because of presence of linolenic acid and linoleic $\operatorname{acid}^{24}$.

- Anti-arthritic activity: The anti-arthritic potential of fenugreek mucilage in adjuvant induced arthritic rats was investigated. There were four groups, group I as control, group II with complete Freund's adjuvant (CFA), group III with CFA and fenugreek mucilage in distilled water (75 mg/kg/day, orally) and group IV with CFA and Indomethacin (3 mg/kg/day, orally). Paw volume was measured plethysmometrically on $7^{\text {th }}, 14^{\text {th }}$ and $21^{\text {st }}$ day. The rats were sacrificed by decapitation on 21st day and blood samples and paw tissue were collected for the assay of inflammatory enzymes such as cyclooxygenase, lipoxygenase, cytokines like IL-6, TNF- $\alpha$, arthritic index and rheumatoid factor (RF). Significant inhibition with $39.4 \%$ on day $7,63.71 \%$ on day 14 and $80.56 \%$ on day 21 was seen and on 21 st day of adjuvant arthritis, fenugreek mucilage showed maximum percentage of oedema inhibition at a dose of $75 \mathrm{mg} / \mathrm{kg}$ when compared with indomethacin. Fenugreek mucilage after twenty-one days to CFA induced rats, it was found that serum RF value was reduced significantly in adjuvant rats when compared to rats of indomethacin administration. Diminished activities of inflammatory enzymes and concentration of mediators were seen with treatment of fenugreek mucilage. Synovial fluid cytology displayed mild inflammation with normal synoviocytes tried to bring back to normal characteristics on supplementation with fenugreek mucilage. The study provided a basis for the usage of fenugreek mucilage that markedly reduces cell influx, release of mediators and $\mathrm{B}$ cell activation associated with arthritic conditions and considered a potent anti-arthritic agent ${ }^{25}$.

- Antibacterial and Anticancer activities: Fenugreek seed extract was investigated for antibacterial activity against six pathological bacteria strains, Staphylococcus aureus, Vibrio parahaemolyticus, Pseudomonas aeruginosa, Proteus mirabilis, Salmonella typhi and Escherichia coli. Biochemical examinations were done using the Vitek2 automated system and diffusion agar method. The anticancer activities of fenugreek seed extract, on MCF-7 breast cancer cells, liver cancer HCAM cells and the non-cancerous Vero cell lines, were inspected through colorimetric MTT assay. Antibacterial activity results exhibited that the highest activity of the extract was found on Staphylococcus aureus and Pseudomonas aeruginosa with 22 mm and 17 mm diameter of inhibition zones respectively. On the other hand, anticancer activity of the extract presented proliferative inhibition on MCF-7 cell line at a concentration of $400 \mu \mathrm{g} / \mathrm{ml}$ and 72 hours of the incubation period followed by insignificant necrosis /apoptosis. However, the seed extract disclosed no anticancer effect on liver and Vero cell lines. The study emphasized on the antibacterial activity of their aqueous and ethanol extract on many pathogenic bacterial strains and anticancer activity through inhibition of more than half of the human breast cancer MCF-7 cell lines for the treatment of breast cancer ${ }^{26}$.

- Hepatoprotective activity: The study demonstrated to be a pilot study and encourages farmers to use fenugreek seeds in domestic animals as a detoxifying diet supplement. Fenugreek seeds against chronic liver injury induced by aluminium chloride (AlCl3) in wistar rats were randomly disseminated into four groups of ten animals each, group I as control, group II with $\mathrm{AlCl} 3$ daily during 5 months at the dose of $500 \mathrm{mg} / \mathrm{kg}$ bw i.g for one month, then 1600 ppm via drinking water, group III with $\mathrm{AlCl} 3$ and fenugreek seed powder at $5 \%$ in standard rat food during the last 2 months and group IV with fenugreek seed powder only. Liver atrophy, inhibition of aspartate transaminase (AST), alanine transaminase (ALT) and glutamyl transpeptidase (GGT), enhancement of both lipid peroxidation and lactate dehydrogenase (LDH) activity and an increase of total protein level was observed in five months of AlCl3 oral exposure $(500 \mathrm{mg} / \mathrm{kg}$ bw i.g for one month then 1600 ppm via drinking water). Histopathological and histochemical findings revealed moderate alterations in the hepatic parenchyma and disruption in iron metabolism. It was also found that co-administration of fenugreek seed powder at 5\% in pellet diet during two months succeeded to antagonize the damaging impacts of AlCl3 by restoring all established parameters ${ }^{27}$.

\section{CONCLUSION AND FUTURE PERSPECTIVES}

Many herbs have been used since ages for the management of diseases in the Unani system of medicine and many of them have been reported to have a higher rate of efficacy and safety when compared to the conventional treatment. Fenugreek showed versatile pharmacological actions with the presence of important bioactive constituents. The known phytochemicals present in fenugreek such as alkaloids, flavonoids, saponins may serve as lead molecules towards the expansion of chemically and metabolically stable molecules with higher pharmacokinetic attribute. Though scientific research into fenugreek pharmacological studies contribution to medical science is a recent phenomenon, its curative properties have long been recorded in Unani 
literature. Several studies conducted in recent years have found some positive results regarding fenugreek role as an effective and safe alternative medicine. The review clearly explained the ethnomedicinal importance of fenugreek for not only serving as herb, food additive and spice, but also as a promising agent to prevent and treat wide range of disorders for health promotion and management. However, additional studies are needed on mechanisms behind the diverse biological activities that have been reported traditionally for its scientific justification. The work explored the pharmacology, phytochemistry, toxicology and traditional uses of Trigonella foenum-graecum L. and authors highly suggest that the herb hold an exceptional medicinal value to be utilized for countless health benefits. As conventional scientists are turning their attention towards indigenous systems of medicine to explore and develop newer agents from plants and their active metabolites, further study on this extraordinary medicinal herb will add new impetus into the research arena.

\section{Funding: None}

\section{Acknowledgments: None}

\section{REFERENCE}

1. World Health Organization, Benchmarks for training in traditional / complementary and alternative medicine, Geneva, 2010; pp-1-2. ISBN 9789241599641.

2. Anonymous, Unani medicine and research trends an insight, Central Council for Research in Unani Medicine, New Delhi, 2020; pp-6-7.

3. Drugs and Lactation Database (LactMed). Bethesda (MD), National Library of Medicine, US, 2006Fenugreek, 2021 Aug 16. PMID: 30000838.

4. Anonymous, The Unani Pharmacopoeia of India. Part I, Vol. IV, Central Council for Research in Unani Medicine, New Delhi, 2008; pp- 51-52.

5. Anonymous, Medicinal plants in folklores of Northern India, Central Council for Research in Unani Medicine, New Delhi,2001; pp-494.

6. Anonymous, Standardisation of single drugs of Unani medicine, part I, Central Council for Research in Unani Medicine, New Delhi,1987, pp-220-225.

7. Zameer S, Najmi AK, Vohora D, Akhtar M. A review on therapeutic potentials of Trigonella foenum graecum (fenugreek) and its chemical constituents in neurological disorders: Complementary roles to its hypolipidemic, hypoglycaemic, and antioxidant potential. Nutritional Neuroscience, 2017;1-7. doi:10.1080/1028415x.2017.1327200.
8. Pruthi JS, Spices and Condiments, National Book Trust, New Delhi, India,2006; pp-131-136.

9. Anonymous, Al Jami Li Mufradat Al Advia wa-al Aghziya (Urdu translation). Second ed. Central Council for Research in Unani Medicine, New Delhi, 2000; pp54-55.

10. Ghani N., Khazainul Advia, vol .1-4. Idara kitab-ulShifa, New Delhi, YNM; pp-1290-1291.

11. Ouzir M., El Bairi K, Amzazi S. Toxicological properties of fenugreek (Trigonella foenum graecum). Food Chem Toxicol. 2016 Oct; 96: 145-54. doi: 10.1016/j.fct.2016.08.003.

12. Anonymous, Standard Unani Medical Terminology. First ed. Central Council for Research in Unani Medicine, New Delhi, 2012; pp-337-365.

13. Sevrin T., Boquien C.Y., Gandon A., Grit I., De Coppet P, Darmaun D., Alexandre-Gouabau M.C.. Fenugreek Stimulates the Expression of Genes Involved in Milk Synthesis and Milk Flow through Modulation of Insulin/GH/IGF-1 Axis and Oxytocin Secretion. Genes (Basel). 2020 Oct 16;11(10):1208. doi: 10.3390/ genes11101208.

14. Gruner O.C., A Treatise on the Canon of medicine of Avicenna, AMS press, New York,1973; pp-363.

15. Azam K., Muhit -i- Azam (Urdu translation). Fourth ed. Central Council for Research in Unani Medicine, New Delhi, 2018; pp-705-706.

16. Dixit P., Ghaskadbi S., Mohan H., Devasagayam T.P.A.. Antioxidant properties of germinated fenugreek seeds. Phytotherapy Research, 2005; 19(11), 977-983. doi:10.1002/ptr.1769.

17. Tewari D., Jóźwik A., Łysek-Gładysińska M., Grzybek W., Adamus-Białek W., Bicki J., Strzałkowska N., Kamińska A., Horbańczuk O.K., Atanasov A.G.. Fenugreek (Trigonella foenumgraecum L.) Seeds Dietary Supplementation Regulates Liver Antioxidant Defence Systems in Aging Mice. Nutrients. 2020 Aug 24;12(9):2552. doi: 10.3390/ nu12092552.

18. Bin-Hafeez B., Haque R., Parvez S., Pandey S., Sayeed I., Raisuddin S. Immunomodulatory effects of fenugreek (Trigonella foenum graecum L.) extract in mice. International Immunopharmacology, 2003; 3(2), 257-265. doi:10.1016/s1567-5769(02)00292-8.

19. Ramadan G., El-Beih N.M., Abd El-Kareem H. F. Anti-metabolic syndrome and immunostimulant activities of Egyptian fenugreek seeds in diabetic/obese and immunosuppressive rat models. British Journal of Nutrition,2010; 105(07), 995-1004. doi:10.1017/ s0007114510004708. 
20. Hadi A., Arab A., Hajianfar H, Talaei B., Miraghajani M., Babajafari S., Tavakoly R. The effect of fenugreek seed supplementation on serum irisin levels, blood pressure, and liver and kidney function in patients with type 2 diabetes mellitus: A parallel randomized clinical trial. Complementary Therapies in Medicine, 2020; 49, 102315. doi: 10.1016/ j.ctim.2020.102315.

21. Zhang H, Xu J, Wang M, Xia X, Dai R, Zhao Y. Steroidal saponins and sapogenins from fenugreek and their inhibitory activity against $\alpha$-glucosidase. Steroids. 2020 Sep; 161:108690. doi: 10.1016/j.steroids. 2020. 108690.

22. Bafadam S., Mahmoudabady M, Niazmand S., Rezaee S.A., Soukhtanloo M. Cardioprotective effects of Fenugreek (Trigonella foenum-graceum) seed extract in streptozotocin induced diabetic rats. J Cardiovasc Thorac Res. 2021;13(1):28-36. doi: 10.34172/ jcvtr.2021.01.

23. Assad T., Khan R.A. Effect of methanol extract of Trigonella foenum-graecum L. seeds on anxiety, sedation and motor coordination. Metab Brain Dis. 2017 Apr;32(2):343-349. doi: 10.1007/s11011-016-9914-y.
24. Pundarikakshudu K., Shah D.H., Panchal A.H., Bhavsar G.C. Anti-inflammatory activity of fenugreek (Trigonella foenum-graecum Linn.) seed petroleum ether extract. Indian J Pharmacol. 2016 JulAug;48(4):441-444. doi: 10.4103/0253-7613.186195.

25. Sindhu G., Shyni G. L., Pushpan C.K., Bala N., Helen A. Evaluation of anti-arthritic potential of Trigonella foenum graecum L. (Fenugreek) mucilage against rheumatoid arthritis. Prostaglandins Other Lipid Mediat. 2018 Sep; 138:48-53. doi: 10.1016/ j.prostaglandins.2018.08.002.

26. Al-Timimi LAN. Antibacterial and Anticancer Activities of Fenugreek Seed Extract. Asian Pac J Cancer Prev. 2019 Dec 1;20(12):3771-3776. doi: 10.31557/APJCP.2019.20.12.3771.

27. Belaïd-Nouira Y., Bakhta H., Haouas Z., Flehi-Slim I, Neffati F., Najjar M.F., Cheikh H.B.. Fenugreek seeds, a hepato-protector forage crop against chronic AlCl3 toxicity. BMC Vet Res. 2013 Jan 31; 9:22. doi: 10.1186/1746-6148-9-22. 